\title{
Individualism-Collectivism And Organisational Value Types: A Case Of Malaysian Managers
}

Fauziah Noordin, Universiti Teknologi MARA, Malaysia Jamil Hamali, Universiti Teknologi MARA, Malaysia

\begin{abstract}
The results showed that Malaysian managers have significantly high levels of horizontal and vertical collectivism. Vertical collectivism has significant positive relationships with collegial, meritocratic, and leadership organisational values.
\end{abstract}

Keywords: Individualism, collectivism, organisational value types

\section{INTRODUCTION}

1 $\mathrm{t}$ is intuitively appealing to believe that some people, because of their cultural membership, would be more likely to exhibit similar behavioural responses in an organisation. Typically, individualism and collectivism are defined in terms of one another, and cultures high in collectivism (for eg., Malaysia) are assumed, explicitly or implicitly, to be low in individualism and vice-versa. For example, East Asian individuals are described as group oriented and promoting the goals of others (Triandis, 1995), emphasising collective identity (Triandis, 1989), and stressing the importance of external and public roles and relatives (Markus and Kitayama, 1994). In contrast, Euro-Americans are depicted as self- oriented and promoting their own goals (Triandis, 1995), emphasising private identity (Triandis, 1989), and focusing on internal abilities, thoughts and feelings (Markus and Kitayama, 1994).

According to Hofstede (1980), the norm prevalent in a given society as to the degree of collectivism expected from its members will strongly affect the nature of the relationship between a person and the organisations he or she belongs to. He further stresses that the level of individualism/collectivism will have several effects on the employees in terms of: (1) More collectivist societies call for greater emotional dependence of members on their organisations, and organisations in return should assume a broad responsibility for their members. Whenever organisations cease to do that, there would be disharmony between people's values and the social order and this would lead either to a shift in values toward more individualism, or collectivist social order (such as state socialism), or both (Hofstede, 1980); (2) The level of individualism / collectivism in society will affect the organisation's members' reasons for complying with organisational requirements. It can be assumed that there will be more "moral" involvement with organisation where collectivism values prevail; and (3) The degree of individualism / collectivism in organisations obviously will depend on many factors besides a societal norm. It can be expected that employee educational level and of the organisation's own history and subculture and organisation's size have effects on individualism/collectivism. According to Hofstede (1980), in stable collectivist societies, members will transfer part of their extended-family or clan allegiance to the organisation they belong to.

Kabanoff (1992) proposed that organisations can be categorised into four culture types: an elite, a leader focused, a meritocratic and a collegial organisational value types. According to Kabanoff (1992), each of these culture types has its own basic set of organisational values. Collegial culture type is the most egalitarian culture in which power, rewards and resources are evenly distributed. This culture relies upon individuals' commitment, participation and adherence to norms as the basis for task-achievement, rather than upon instrumental rewards, and the organisation exercises relatively little direct control over people's activities. Meritocratic culture type shares 
many of the egalitarian qualities of the collegial culture, but with increased emphasis on performance and rewarding people for performance. A set of equity values overlays a set of collegial, interpersonal values. Elite type is the most inegalitarian, most differentiated culture with power, resources and rewards concentrated at the apex. Instrumental values dominate social values. Finally, leader-focused culture type is unequal in its distribution of power, rewards and resources. It builds cohesion by creating a team system around a cadre of loyal leaders who are delegated some of the elite's power. Loyalty rather than equality is the main 'glue.' To date hardly any research has been conducted to assess the relationships between individualism-collectivism and organisational value types. The present study addresses the needs to study these relationships.

\section{Individualism-Collectivism and Organisational Value Types}

Parson and Shils (1951) suggested the concepts of individualism-collectivism as a way to distinguish between individuals who are oriented more towards self-interest and reaching their own goals and individuals who are oriented toward the collective and focus on the social system rather than themselves. Singelis, Triandis, Bhawuk and Gelfand (1995) developed an individualism-collectivism scale that measures both the horizontal and the vertical dimensions of individualism-collectivism. Triandis (1995) argues that it is important to make the distinction between vertical and horizontal individualism-collectivism. He defines horizontal collectivism as a cultural pattern in which the individual sees the self as an aspect of an in-group. That is, the self is merged with the members of the in-group, all of whom are extremely similar to each other. In this pattern, the self is interdependent with and the same as the self of others. Equality is the essence of this pattern. Vertical collectivism, on the other hand, is a cultural pattern in which the individual sees the self as an aspect of an in-group, but the members of the in-group are different from each other, some having more status than others. The self is interdependent with and different from the self of others. Inequality is accepted in this pattern, and people do not see each other as the same. Serving and sacrificing for the in-group is an important aspect of this pattern. Triandis (1995) refers to horizontal individualism as a cultural pattern where an autonomous self is postulated, but the individual is more or less equal in status with others. The self is independent and the same as the self of others. Vertical individualism, on the other hand, is a cultural pattern in which an autonomous self is postulated, but individuals see each other as different, and inequality is expected. The self is independent and different from the self of others. Competition is an important aspect of this pattern.

Kabanoff (1995) theorises that more people within a particular culture will tend to have work experiences that reflect the practices, structures and conditions that are associated with those of a particular organisational type and this shapes their values and attitudes as well as reinforcing the values they have been socialised in. Kabanoff (1995) argues that the different types of organisations can be recognised by the different values they possess and which are shaped by the surrounding national culture. He substantiates this argument by integrating the model of organisational types (Kabanoff, 1991, 1993) with Hofstede's (1980) individualism-collectivism and power distance dimensions of culture. Based on this integrated model, different types of organisations are assumed to be more or less prevalent in different national cultures. This also implies that organisational values form an important bridge or link between national values and values and the behaviour of organisations as well as groups and individuals in organisations.

Kabanoff (1995) predicts that leadership-oriented, teamwork-based organisations are more prevalent in Hofstede's (1980) high-power distance, low individualism cultures. Collegial organisations should be characteristic of (relatively) less individualistic, low power distance cultures. Elite organisational type are more prevalent in a high power-distance, high individualism countries, whereas meritocratic organisational types are more prevalent in a low power distance, high individualism nations. The theory of organisational types and its associated espoused organisational values referred to here have been described in detail elsewhere (see Kabanoff, 1991, 1993; Kabanoff, Waldersee, and Cohen, 1995).

Based on the discussion above, three objectives were outlined for this study: (1) To determine the level of collectivism / individualism of Malaysian managers (2) To examine the relationships between horizontal and vertical dimensions of individualism and collectivism and types of organisational values espoused in organisations in Malaysia and (3) To assess the relative importance of demographic variables on horizontal and vertical dimensions of individualism and collectivism and types of organisational values. 


\section{RESEARCH METHODOLOGY}

\section{Subjects and Data Collection}

Data was collected by questionnaire from middle managers in a total of 18 organisations in Selangor, Malaysia. Each organisation was mailed 15 questionnaires. The mail survey was administered in accordance with the principles and procedures advocated by Dillman (1977), and the administrative procedure recommended by Chan (1992). The organisations used their discretion in distributing the questionnaires to employees who met the definition of "a manager" we supplied. After exclusion of inappropriate and unusable responses, a final analytical sample of 203 was obtained, resulting in effective response rates of $75 \%$.

\section{Questionnaire Instruments}

Individualism-collectivism was measured using Singelis, Triandis, Bhawuk, and Gelfand's (1995) 32-item scale. The items in the scale are designed to measure the horizontal and vertical aspects of individualismcollectivism. The scale is divided into four dimensions - vertical individualism, horizontal individualism, vertical collectivism, and horizontal collectivism - with eight items in each dimension. The items were answered on 7-point scales, where 1 indicates strong disagreement and 7 indicates strong agreement.

Kabanoff's (1995) Survey of Organisational Values was used to assess organisation's value orientation with respect to five different aspects: the "Role of managers", "Providing direction and co-ordination", 'What binds people to the organisation", "The nature of relationships", and "Organisational rewards". Each of the different aspects were described in four different ways with each description corresponding to each of the four types of organisations, that is, collegial, meritocratic, leadership, and elite. The measures used 5-point Likert scale response format ( $5=$ exactly like; $4=$ a bit like; $3=$ unlike; $2=$ not at all like; and $1=$ don't know). A set of items asking about demographic information data was prepared.

\section{Results and Discussion}

\section{i. Descriptive Statistics}

Table 1 presents the means, standard deviations, reliabilities and correlations for the 8 measures. The results indicate that Malaysian managers perceived themselves as high in horizontal collectivism (6.00), moderate in vertical collectivism (4.92), horizontal individualism (4.88), and vertical individualism (4.72). The levels of organisational value types espoused by the Malaysian managers appear to be at moderate levels (collegial = 3.68 ; meritocratic $=3.86$; leadership $=3.78$; and elite $=3.66$ ). Table 1 also indicate that horizontal individualism is significantly and positively correlated with vertical individualism $(r=.16)$; vertical individualism is significantly and positively correlated with and meritocratic organisational value type $(r=.18)$; horizontal collectivism is significantly and positively correlated with vertical collectivism $(r=.36)$, collegial organisational value type $(r=$ .19 ), and meritocratic organisational value type $(r=.16)$; vertical collectivism is significantly and positively correlated with collegial organisational value type $(r=.24)$, meritocratic organisational value type $(r=.17)$, and leadership organisational value type $(r=.17)$.

Table 1: Mean, Standard Deviations, Reliabilities And Correlations Of Measures

\begin{tabular}{|l|c|c|c|c|c|c|c|c|}
\hline \multicolumn{1}{|c}{ Measures } & $\mathbf{1}$ & $\mathbf{2}$ & $\mathbf{3}$ & $\mathbf{4}$ & $\mathbf{5}$ & $\mathbf{6}$ & $\mathbf{7}$ & $\mathbf{8}$ \\
\hline 1. Horizontal individualism & $\mathbf{. 5 6}$ & & & & & & & \\
2. Vertical Individualism & $.16^{*}$ & $\mathbf{. 5 8}$ & & & & & & \\
3. Horizontal Collectivism & -.08 & .09 & $\mathbf{. 6 7}$ & & & & & \\
4. Vertical Collectivism & -.05 & .05 & $.36^{* *}$ & $\mathbf{. 6 3}$ & & & & \\
5. Collegial & .01 & .13 & $.19^{* *}$ & $.24^{* *}$ &. $\mathbf{7 9}$ & & & \\
6. Meritocracy & .05 & $.18^{*}$ & $.16^{*}$ & $.17^{*}$ & $.82^{* *}$ & $\mathbf{. 8 2}$ & & \\
7. Leadership & -.06 & .10 & .08 & $.17^{*}$ & $.35^{* *}$ & $.70^{* *}$ &. $\mathbf{7 4}$ & \\
8. Elite & .12 & .03 & .11 & .13 & .07 & $.21^{* *}$ & $.37^{* *}$ & $\mathbf{. 6 4}$ \\
& & & & & & & & \\
Mean & 4.88 & 4.72 & 6.00 & 4.92 & 3.68 & 3.86 & 3.78 & 3.66 \\
S.D. & .97 & 1.04 & .59 & .95 & .73 & .73 & .70 & .66 \\
\hline
\end{tabular}

$* p \leq .05 ; * * p \leq .01$ (2-tailed). Reliabilities estimates (coefficient alpha) are shown in the diagonal (in bold). 


\section{ii. Individualism-Collectivism: Independent Groups T-test Among Major Variables of Interest and Demographic Variables}

\section{Nationality of Top Management Officer}

Malaysian managers who have Westerners as their top management officers appear to have a higher level of horizontal individualism than those who have Asians as their top management officers. Westerners are often cited in the literature as having individualistic characteristics (see Hofstede, 1980, Triandis, 1995; Schwartz, 1994). The 'secular spirituality' of the west resulted in self-responsible individuals acting, not in terms of laws from the outside, but in terms of a developing realisation of self-worth (Triandis, 1995).

Furthermore, most of the people of the West are characterised by individualism in everyday life, and these individualistic elements may have been introduced into the organisational culture which, in turn, may influence the characteristics of the employees to a certain extent. Collectivists tend to change themselves to fit into situations (Diaz-Guerrero, 1979, 1991; Diaz-Guerrero and Diaz-Loving, 1990). Malaysian managers learn to change themselves to fit into the environment created by their Western top management officers and, therefore, embrace some of the individualist characteristics. Whether such an influence affects only the work situations, or extends to social/family situations, will require further study.

\section{Gender}

It should be noted that there is no significant difference between Malaysian male and female managers in terms of individualism-collectivism dimensions.

Table 2: Independent Groups T-Test

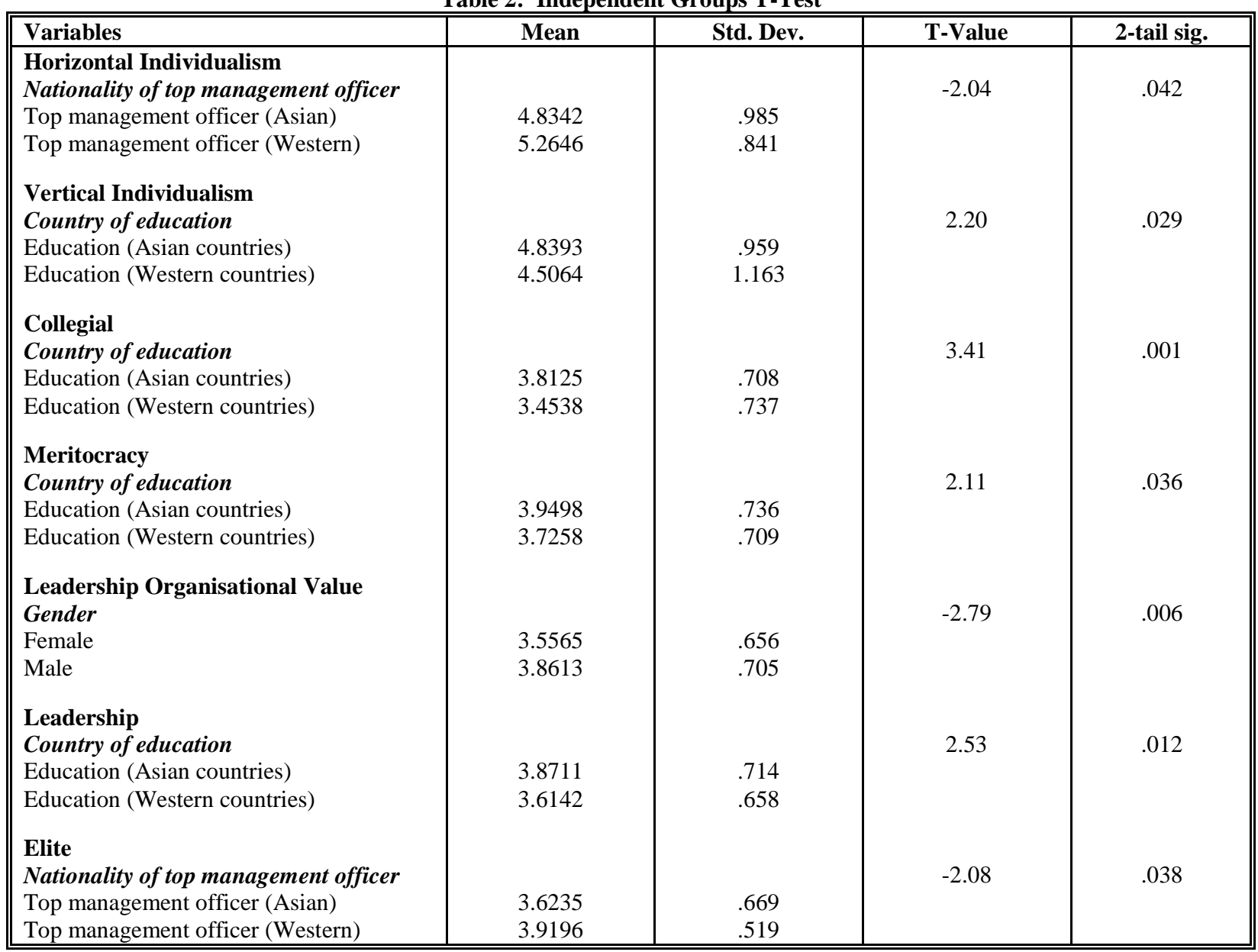


Raja Rohana (1991) noted that the hardships of World War II had led to a willingness to allow women in Malaysia to take external jobs. Prior to that, women in Malaysia generally worked on the cultivation of crops and the tending of domestic animals, except for a small number of women who worked in the market place and in small businesses (Halinah, 1975). Malaysia's Independence from the British rule in 1957 had gradually but profoundly affected women's lives throughout Malaysia. The New Economic Policy, implemented 13 years after Independence, resulted in more schools and more jobs. There were scholarships for women to pursue education in local and foreign universities. Today, women in Malaysia work in offices and have professional careers. Education has given Malaysian women freedom and knowledge and skills necessary to have a career outside the home. Malaysian women's participation in the labour force may lead inevitably to lower commitment to marriage and the home environment, which "individualises" women. This might explain the lack of difference between the Malaysian males and females in relations to individualism-collectivism.

\section{Country of Education}

According to Triandis (1995) education generally leads to greater exposure to cultural diversity and tends toward individualism. However, the more traditional educated (Sunday School, Quranic School, language of own ethnic group) a person is, the more collectivist the person becomes. Education in Malaysia has developed along the British model. In Malaysia, the educational system is more pragmatic and secular (Hashim, 1996) and religion is but one of the many subjects taught. Furthermore, given the pervasive Asian competitive achievement orientation toward educational admissions and organisational placements, those with greater education accomplishments will expect and receive greater rewards (job, salary, status). Educational systems in Asian countries may further influence the acceptance of individualistic values of competition and achievement orientation. An additional factor worth considering is that Malaysians may have found a "niche" in intellectual activities. Through education and hard work they can secure a good life, and both education and hard work are compatible with the Islamic and Confucian values.

Hashim (1996) observes that the Malaysian education system is plagued with a 'diploma' or 'certificate' disease, which is the frenzied chasing after paper credential because of their presumed value in getting employment and the prestige attached to them. Diplomas or certificates generally are awarded for achievements in the cognitive domain and through external examinations. Little recognition is given to excellence in the affective, moral, or social domain. There is a lack of cultivation of the social spirit, and the nature of evaluation inculcates individual competition for external standing. This individual competition starts as early as at the primary school.

Another possible explanation is the curricula implemented in schools, colleges and universities in Malaysia and other Asian countries. These curricula are often modelled on American or European models (Westwood, 1992). Educational models, technology, methods, and contents are imported from the West and majority of textbooks (management books in particular) used in educational institutions in Malaysia are of American or United Kingdom origin. Unfortunately, most of these textbooks have not been written for the local situations. Most have not even been written an international audience. In this respect, the Malaysian managers who had their formal education in Malaysia or other Asian countries would almost certainly have been heavily exposed to Western theories, practices and materials. In sum, the "diploma disease" together with the Malaysian managers' exposure to Western management theories and practices in their education have made the influence of individualism strong and cumulative.

\section{Organisational Value Types: Demographic Variables}

\section{Gender}

The t-test (Table 2) results show that Malaysian male managers appeared to perceive their organisation to have a higher level of leadership organisational value type than their female counterparts. The leadership value type, while unequal in its distribution of power, rewards and resources seeks to build integration through the creation of a system of leadership and teamwork throughout the organisation by having a loyal band of leaders below the apex, who are delegated some power (Kabanoff, 1993). The male Malaysian managers' perception that their organisations have the leadership organisational value type could be because superiors in their organisations prefer 
to delegate powers to the male rather than to the female managers, believing that male managers are more qualified, physically and mentally, to do the job. This undermining of the female managers ability and capability to do their jobs is still prevalent in organisations in Malaysia. Since the leader-focused value type places a heavy emphasis on performance evaluation and reward systems, the favoured male managers would have a more favourable performance evaluation results than their female counterparts and would receive higher rewards. The occurrence of this type of situation may have influenced the male managers in Malaysia to perceive their organisations to have a higher level of leadership organisational value type than their female colleagues.

\section{Country of Education}

Being educated locally in one's country means being constantly exposed to and exhibiting the local culture, be it individualism or collectivism, in a person's daily life. The t-test results (Table 2) show that those managers who were educated in Asian countries perceived their organisation to have more collegial, leadership, and meritocratic organisational value types than those who were educated in western countries. One possible explanation for this could be the Malaysians strong affinity for group affiliation (Abdullah \& Singh, 1992). Malaysians derive their identity from being part of a collectivity. Malaysians are motivated by their affiliations to groups, families, friends, hometown and nation. They respect efforts to improve productivity if they can see benefits accruing not only to the organisation but also to their family, community and nation. Most Malaysians are interested with building and maintaining good relationships with those they work with. They are often contented at work if they have the opportunity to show and receive appropriate recognition and respect from their superiors, peers and subordinates. Three of the four types of organisational values (collegial, meritocratic and leadership) have affiliation as a value that is strongly espoused by the organisation. Since, Malaysians have a strong affinity for group affiliation, this could perhaps explain why Malaysian managers, educated locally and in other Asian countries, perceived their organisations to have higher levels of collegial, meritocratic and leadership organisational value types.

\section{Nationality of Top Management Officer}

The t-test results (Table 2) show that those Malaysian managers who have Westerners as their top management officers perceive their organisations as having a higher level of elite organisational value type than those who have Asians as top management officers. Malaysian managers may have perceived their Western top management officers as belonging to a Western elite group. They may have perceived that a Western leader to be a more effective leader with the expertise and technical competence that comes along with the ability to get the job done. Malaysians prefer to be led by those they feel are committed to their objectives through the words they use and actions they demonstrate (Abdullah and Singh, 1994). Organisations in Malaysia are very hierarchical and bureaucratic in nature. Also, authoritarian style of management is still predominant in Malaysia. Power and authority are concentrated at the top and are usually not questioned or challenged. These factors may have influenced the Malaysian managers' perception that their organisations are espousing the elite type of organisational values.

\section{Individualism-Collectivism: One Way Between Groups ANOVA with Post-Hoc Comparison}

Age

Post-Hoc comparisons (Table 3) found that "age group" has a significant impact on vertical collectivism for the Malaysian managers. Those who are older than 44 years old tend to have a higher level of vertical collectivism. In the only American study to examine this relationship (Noricks, et al., 1987), collectivism increased after age 55. In some societies, age has status connotations. In such societies, the older the person the more likely he/she will be respected. Also, some societies believe that the older one gets, the wiser one becomes (Harris and Moran, 1991). Yamaguchi (1994), using Japanese students as his sample, found that collectivism score is positively correlated with age. He concludes that older Japanese are more collectivistic than younger Japanese. A parallel finding was obtained by Triandis (1988), evaluating Japanese students who were individualists and their parents who were collectivists. 


\section{Organisational Value Types: One Way Between Groups ANOVA with Post-Hoc Comparison}

Age

The Post-Hoc comparisons (Table 3) show that Malaysian managers who were in the "more than 44 years" age group perceived their organisations as having the meritocratic organisational value type more than those in the "31-44 years" age group.

Table 3: One Way Between Groups ANOVA With Post-Hoc Comparisona)

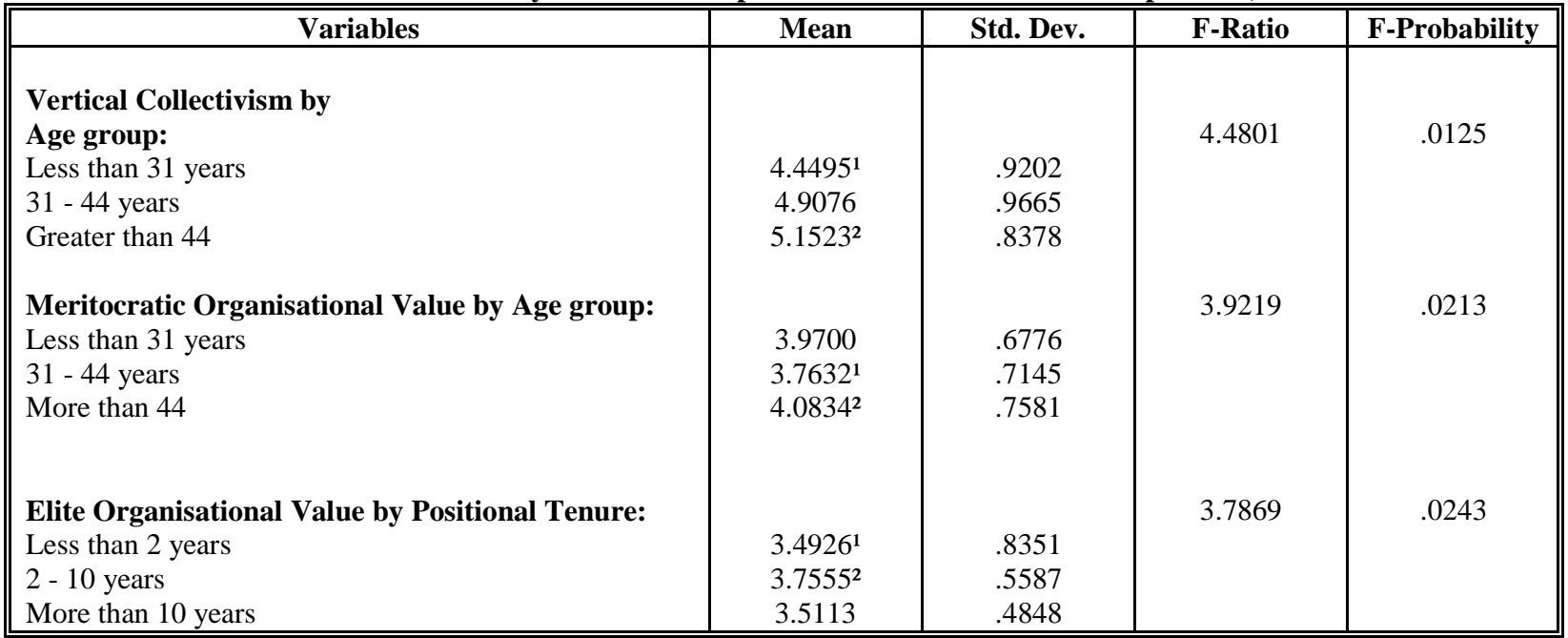

Note: Those means with different superscripts differ significantly $(\mathrm{p}<.05)$. Those that share a superscript, or for which no superscripts appear, are not significantly different from each other $(\mathrm{p}>.05)$.

a. Modified LSD (Bonferroni) test with significance level .05

Malaysian managers in the "more than 44 years" age group can be categorised as being in the maintenance stage of their career (Morrow \& McElroy, 1987). At this stage, these people have established good rapport with the management, good teamwork, a great deal of positive and equitable organisational experience, and have secured higher managerial positions in the management level and therefore, reducing the power distant between themselves and the next higher management level. Based on this, the Malaysian managers in the "more than 44 years" age group may have perceived that their organisation is practising a meritocratic type of organisational value.

\section{Positional Tenure}

Post-Hoc comparison shows that Malaysian managers who have between 2 - 10 years of positional tenure perceived their organisations as having a higher elite organisational value type than those who have positional tenure of less than 2 years. Malaysian managers in the '2-10 years' of positional tenure can be categorised as being in the advancement stage of their career (Morrow and McElroy, 1987). At this stage, Malaysian managers have usually established themselves with their respective careers, work roles and its organisational demands, and have become acquainted with potential commitment targets within the workplace (Morrow and McElroy, 1987). The focus at this stage would be on upward mobility, additional responsibility, promotion and other related areas. The challenges and realisation of the opportunity for upward mobility may influence the Malaysian managers' expectations that their organisations espoused an elite type of organisational value. The outcomes of their expectations in relation to their upward mobility in their organisations would confirm/disconfirm their perception on the type of organisational values espoused by their organisations. 


\section{CONCLUSIONS AND RECOMMENDATIONS}

One purpose of the present study was to determine whether the reported categorisation of Malaysia as a collectivist country (Hofstede, 1980, 1984; Schwartz, 1994; Triandis, 1995) holds true. The results showed that Malaysia has significantly high levels of horizontal and vertical collectivism. This supports the contention that Malaysian society is a collectivistic society.

Overall, the findings of the present study suggest that there have been significant shifts in value classifications in Malaysia since Hofstede $(1980 ; 1984)$ conducted his original study. This finding underscores the fact that, although a nation's work-related values and attitudes are deep-seated preferences for certain end states, they are subject to change over the years as external environmental changes shape a society. Therefore, researchers and practitioners should use caution before attempting to use work-related values and attitudes to understand human behaviour in organisations. At the least, managers should make an effort to determine the values and attitudes currently prevailing and not rely on classifications or labels placed on cultures by previous researchers.

The findings also highlight the importance of measuring horizontal and vertical dimensions of individualism and collectivism. Without the measurement of both, the study would not have been able to detect the differences that it did. Similarly, where the study found that the Malaysians inclination towards collectivism has changed slightly over the years and this would not have been possible had it not measured them. Thus, the measurement of the horizontal and vertical dimensions of individualism and collectivism is important for predicting and explaining both findings and non-findings.

The importance of demographic variables, as relating directly to individualism-collectivism and organisational value types, indicate that such variables do serve, as Landy et al. (1984) maintain, as effective "surrogate" variables whose inclusion in explanatory models of work attitudes is advisable. This is especially useful in exploratory studies, where they suggest avenues for further research on the more basic psychological processes which they apparently represent. It is interesting to note that most of the demographic variables have different influences on the study variables. Therefore, by including demographic variables in a study, more information can be gained on their influence on the horizontal and vertical dimensions of individualism and collectivism and types of organisational values.

The results of this study are important for three reasons. First, they provide empirical corroboration of the theoretical perspectives of Singelis, Triandis, Bhawuk, and Gelfand (1995) on individualism-collectivism and organisational value types (Kabanoff 1992) respectively. Second, they may be of interest and assistance to managers of multinational and international organisations who need to manage in global contexts and, therefore, need to understand culturally-driven differences in personal and interpersonal work-related conditions between and across nations. Third, the results suggest some different ways in which managers may use collegial, meritocratic, leadership, and elite organisational value types and methods in different nations.

Since only middle managers were used as samples in this study, this raises the issue of generalisability of findings. However, for this study, data were obtained from a variety of organisations in different industries and a variety of middle managers (in terms of age, organisational tenure, and positional tenure). Thus, the author is confident that the findings of the study are generalisable to middle managers. Nevertheless, more research is needed before firm generalisable implications for middle managers can be drawn. Generalisability of the results of these analyses for employees in the non-managerial position remains an open empirical question. Additional replication using a more careful comparison by types of workers and types of occupation would be useful.

\section{AUTHOR INFORMATION}

Fauziah Noordin is a professor of Human Resource Management at the Faculty of Business, Universiti Teknologi MARA, Malaysia. She earned her PhD in Human Resource Management from Queensland University of Technology, Australia. Currently, she is the Assistant Vice Chancellor (Leadership) of the Institute of Leadership and Quality Management at the Universiti Teknologi MARA, Malaysia. Her research interests are focused on various aspects of organisational behavior, human resource management, education, and intercultural research. 
Jamil Hamali is the Director of Universiti Teknologi MARA, Sarawak Branch, Malaysia. He completed his PhD at the University of Salford, United Kingdom. His research is focused on quality management, education, human resource management, and performance management

\section{REFERENCES}

1. Abdullah, A. and Singh, S. (1992). Leading and motivating. In A. Abdullah (ed.), Understanding the Malaysian workforce: Guideline for managers (pp. 33-48). Kuala Lumpur: Malaysian Institute of Management.

2. Chan, Y. E. (1992). Business strategy, information system strategy, and strategic fit: Measurement and performance impacts. Unpublished dissertation. The University of Western Ontario.

3. Diaz-Guerroro, R. (1979). The development of coping style. Human Development, 22, 320-331.

4. Diaz-Guerroro, R. (1991). Mexican ethnopsychology. Paper presented at the $20^{\text {th }}$. Meeting of the Society for Cross-Cultural Research, Puerto Rico,

5. Diaz-Guerroro, R. and Diaz-Loving, R. (1990). Interpretation in cross-cultural personality assessment. In C. R. Reynolds and R. W. Kampaus (eds.) Handbook of psychological and educational assessment of children: Personality, behaviour, and context (pp. 491-523). New York: Guilford Press.

6. Dillman, D. (1977). Preference surveys and policy decisions: Our new tools need not be used in the same old way. Journal of the Community Development Society, 8, 30-43.

7. Harris, R. R. and Moran, R. T. (1991).Managing cultural differences. Houston, Tex.: Gulf Publishing.

8. Hashim, R. (1996). Educational dualism in Malaysia: Implications for theory and practice. Kuala Lumpur: Oxford University Press.

9. Hofstede, G. (1980). Culture's consequences. Beverly Hills, CA: Sage Publications.

10. Kabanoff, B. (1991). Equity, equality, power, and conflict. Academy of Management Review, 16, 416-441.

11. Kabanoff, B, (1992). Identifying organisations' distributive culture using content analysis. Working Paper No. 92-023 University of New South Wales, Australian Graduate School of Management, 1-45.

12. Kabanoff, B. (1993). An exploration of espoused culture in Australian organisations (with a closer look at the banking sector). Asia Pacific Journal of Human Resources, 31, 1-29.

13. Kabanoff, B. (1995). Organisational justice across cultures: Integrating organisational-level and cultural level perspectives. Working Paper 95-024 University of New South Wales, Australian Graduate School of Management.

14. Kabanoff, B., Waldersee, R., \& Cohen, M. (1995). Espoused organisational values and organisational changing themes. Academy of Management Journal, 38, 1075-1104.

15. Landy, F. J., Vassey, J. J., and Smith, F. D. (1984). Methodological problems and strategies in predicting absence. In P. S. Goodman and R. S. Atkins (Eds.), Absenteeism. San Francisco: Wiley.

16. Markus, H., \& Kitayama, S. (1991). Culture and self: Implications for cognition, emotions, and motivation. Psychological Review, 98, 224-253.

17. Morrow, P. C., and McElroy, J. C. (1987). Work commitment and job satisfaction over three career stages. Journal of Vocational Behaviour, 30, 330-346.

18. Noricks, J. S., Agler, L. H., Bartholomew, M., Howard-Smith, S., Martin, D., Pyles, S., and Shapiro, W. (1987). Age, abstract thinking, and the American concept of person. American Anthropologist, 89, 667675.

19. Raja Rohana, R. M. (1991). The role of status of Malay women in Malaysia: Social and legal perspectives. Kuala Lumpur: Dewan Bahasa dan Pustaka.

20. Schwartz, S. H. (1994). Are there universal aspects in the structure and contents of human values? Journal of Social Issues, 50, 19-45.

21. Singelis, T. M., Triandis., H. C., Bhawuk, D. P. S., \& Gelfand, M. J. (1995). Horizontal and vertical dimension of individualism and collectivism: A theoretical and measurement refinement. Cross-Cultural Research, 29, 240-275.

22. Triandis, H. C. (1989). The self and social behaviour in differing cultural context. Psychological Review, 96, 506-520.

23. Triandis, H. C. (1995). Individualism and collectivism. Boulder, CO: Westview. 
24. Triandis, H. C., Bontempo, R., Villareal, M., Asai, M., and Lucca, N, (1988) Individualism and collectivism: Cross-cultural perspectives on self-ingroup relationships. Journal of Personality and Social Psychology, 54, 323-338.

25. Yamaguchi, S. (1994). Collectivism among the Japanese: A perspective from the self. In U. Kim, H. C. Triandis, C. Kagitcibasi, S. C. Choi, \& G. Yoon (Eds.), Individualism and collectivism: Theory, method and applications, (pp. 178-188). Thousand Oaks, CA: Sage.

\section{NOTES}

